EVS25

Shenzhen, China, Nov 5-9, 2010

\title{
A Multi-hybrid Energy System for Hybrid Electric Vehicles
}

\author{
Xiaodong Zhang, K. T. Chau, and C. C. Chan \\ Department of Electrical and Electronic Engineering, the University of Hong Kong \\ Hong Kong Special Administration Region, China \\ xiaodong@eee.hku.hk
}

\begin{abstract}
Recently the thermoelectric-photovoltaic (TE-PV) hybrid energy system for hybrid electric vehicles has been proposed. However, the output voltage of this TE-PV hybrid energy system is governed by the voltage of the battery, which is affected by the state of charge of the battery and the charging/discharging current. Furthermore, in order to improve the power density and life cycle of the battery, the ultracapacitor (UC) has been proposed to hybridize with the battery to form a hybrid energy storage system. In this paper, a multi-hybrid energy system is proposed for HEVs, which incorporates the advantages of the TE-PV hybrid subsystem and the ultracapacitor-battery (UC-B) hybrid subsystem. On the one side, the TE-PV hybrid subsystem can provide the higher fuel economy due to the increase of on-board renewable energy, the better energy security due to the use of multiple energy sources, and the higher control flexibility due to the coordination for charging the same pack of batteries. On the other side, the UC-B hybrid subsystem can provide faster transient power, higher power density and longer battery lifetime. Detailed simulations results are given to highlight the effectiveness of the designed multi-hybrid energy system.
\end{abstract}

Keywords: Hybrid electric vehicles, hybrid energy system, thermoelectric, photovoltaic, multiple input converter

\section{Introduction}

In recent years, there has been active research on exhaust gas waste heat energy recovery for hybrid electric vehicles (HEVs) [1]-[4]. Meanwhile, the use of solar energy is also proposed to promote on-board renewable energy and hence to improve their fuel economy [5]-[6]. These kinds of energy sources can be used to online feed various automotive electronics or charge the battery for storage, hence reducing the oil consumption and the carbon emission of the automobiles.
Benefited from the photovoltaic effect and the Seebeck effect respectively, the photovoltaic (PV) panels and thermoelectric (TE) modules can directly convert the solar energy and heat energy to electrical energy [7]. As a relatively mature technology, the PV generator (PVG) has already been wildly employed in many fields and in many years, while the TE generator (TEG) has more restraints only for the application with sufficient heat sources or waster heat sources. However, the TEG has unique advantages of being maintenance free, silent in operation, independent on weather or topography and involving no moving and complex 
mechanical parts, compared with other power generators like gasoline motor-generator, hydropower generator and wind turbine [8]-[13]. In the past years, many applications have been reported on the TEG, where the PVG can also been applied.

The concept of energy hybridization has been accepted for HEVs [14]. Compared with individual energy sources, the hybrid energy system can offer some definite advantages for automobiles, namely the higher fuel economy due to the increase of on-board renewable energy, the better energy security due to the use of multiple resources, and the higher control flexibility due to the coordination for charging the same pack of batteries [15].

A number of topologies of power conditioning circuits (PCS) for small scale power generators have been proposed in the last decades [16]-[18]. However, these topologies can not meet the requirements of the hybrid energy sources [19], [20]. The multiple-input converters (MICs) can be used to interface the energy sources and the load as the power conditioning circuit [21]. This class of DC-DC converters can simultaneously handle multiple inputs, and regulate the output voltage or current. Consequently, the thermoelectric-photovoltaic (TE-PV) hybrid energy system for HEVs has been proposed [22]. This TE-PV hybrid energy system enables both the TEG and PVG simultaneously achieving the maximum output power with the designed power conditioning circuit.

In this kind of TE-PV hybrid energy system, a battery is connected with the load in parallel to maintain stable output voltage and serve as the energy storage device. Consequently, the output voltage of this TE-PV hybrid energy system is governed by the voltage of the battery, which is affected by the state of charge of the battery and the charging/discharging current [23]. On the other hand, in order to improve the power density and life cycle of the battery, the ultracapacitor (UC) has been proposed to hybridize with the battery to form a hybrid energy source [24]. Few algorithms for the power assignment between the battery and UC have been reported [25]. The low-pass filter control strategy can ensure that the transient current demand is processed by the UC using a low-pass filter, which stabilize the output power of the battery and potentially extend its life time [26]-[27].
In this paper, a multi-hybrid energy system is proposed for HEVs, which incorporates the advantages of the TE-PV hybrid subsystem and the ultracapacitor-battery (UC-B) hybrid subsystem. On the one side, the TE-PV hybrid subsystem can provide the higher fuel economy, better energy security, and higher control flexibility. On the other side, the UC-B hybrid subsystem can provide faster transient power, higher power density and longer battery lifetime. Simulation results are given to show the performances and illustrate the merits of the proposed multi-hybrid energy system.

\section{Multi-hybrid Energy System}

The proposed power conditioning circuit is shown in Figure 1. The TE-PV subsystem is realized by a Cuk-Ćuk MIC, while the UC-B subsystem is by a bidirectional buck-buck MIC.

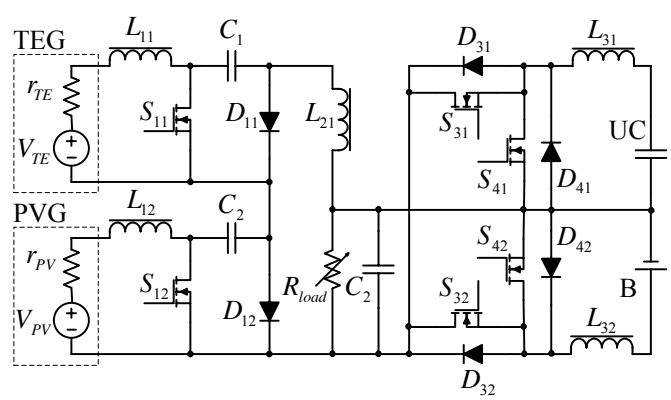

Figure 1: Proposed multi-hybrid energy system.

\subsection{TE-PV Subsystem}

The Ćuk-Ćuk MIC is selected for power conditioning of the TEG and PVG, which functions to track the maximum power point of the TEG or PVG. First, the output voltage of the TEG or PVG may widely and dynamically vary with external physical factors. The Ćuk converter having both step-up and step-down characteristics can handle a wide range of input voltage variation caused by different temperature differences and insolation levels. Second, when the switch is turned off, the Ćuk converter can inherently block the DC input from the TEG or PVG energy sources to the load due to the existence of the intermediate capacitor. Third, both of the input current and output current of the Ćuk circuit are non-pulsating. By properly winding the input and output inductors on the same core, the ripple amplitude can be reduced to zero. This merit can 
significantly minimize the disturbance on the TEG or PVG operating points, and potentially enhance the battery life.

The Ćuk converter can be operated in three modes: continuous current mode (CCM), discontinuous inductor current mode (DICM), and discontinuous capacitor voltage mode (DCVM). Generally, the CCM is more suitable for high voltage, high current input application; the DICM is for high voltage, low current input application; and the DCVM is for low voltage, high current input application. Since the TEG and PVG are of low output voltage, hence low input voltage for the Cuk-Ćuk MIC, it is preferred to operate in the DCVM mode. The input resistances of the Ćuk-Ćuk MIC in the DCVM mode are impressed as following [6]:

$$
\begin{aligned}
& r_{T E}=\frac{T_{s}}{2 C_{1}}\left(1-D_{1}\right)^{2} \\
& r_{P V}=\frac{T_{s}}{2 C_{2}}\left(1-D_{2}\right)^{2}
\end{aligned}
$$

where $T_{s}$ is the switching period, $D_{1}$ and $D_{2}$ are the duty cycles of the switch $S_{1}$ and $S_{2}$, separately.

By tuning the duty cycles of the PWM switching signal to enable the input resistance equal to the internal resistance of the energy source, the maximum power point tracking (MPPT) can be performed. The hill climbing method is used for MPPT, which is based on the fact that only one maximum power point (MPP) of the TEG and PVG exists in the specific circumstances. If the $d P / d V$ is positive, it means the operating point is on the left side of the MPP. Then, the duty cycle should be deduced according to (1) and (2). On the contrary, if the $d P / d V$ is negative, the operating point is on the right side of the MPP. Then, the duty cycle should be increased. Until $d P / d V$ equals zero, the operating point is on the MPP. The algorithm of the hill climbing method is written as:

$$
D_{k+1}=D_{k}-\operatorname{sgn}\left(\Delta P^{*} \Delta V\right) \Delta D
$$

where $D_{i}$ is the switching signal duty cycle, $\Delta P=P_{k}-P_{k-1}$, and $\Delta V=V_{k}-V_{k-1}$ are the input power and voltage difference at the sampling instant $i$, respectively, and $\Delta D$ is initialized as $0.2 \%, \quad i=1,2, \cdots k-1, k, k+1, \cdots \quad$. The MPPT diagram is shown in Figure 2.

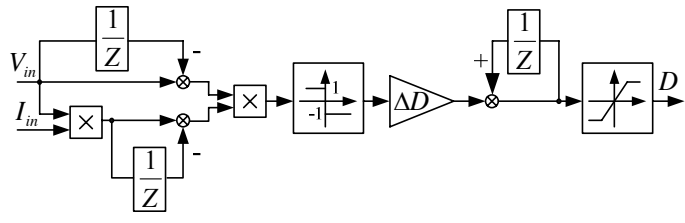

Figure 2: MPPT diagram.

\subsection{UC-B Subsystem}

The paralleled bidirectional buck converter is used to interface the storage device with the DC bus. If the bus voltage is higher than the presetting voltage level, the switches $S_{31}$ and $S_{32}$ are controlled to charging the battery and UC. While the bus voltage is lower than the presetting voltage level, the switches $S_{31}$ and $S_{32}$ are controlled to discharging the battery and UC. The power balance control diagram is illustrated in Figure 3.

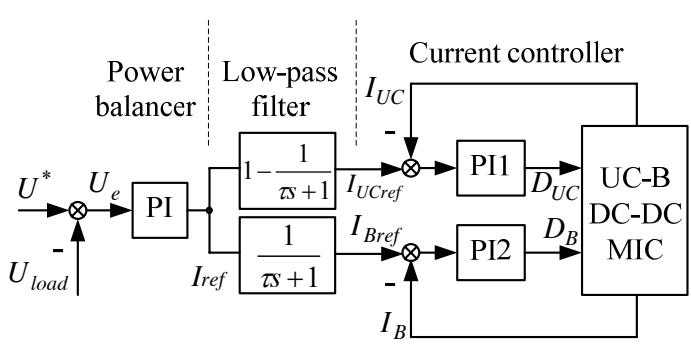

Figure 3: Power balance control diagram.

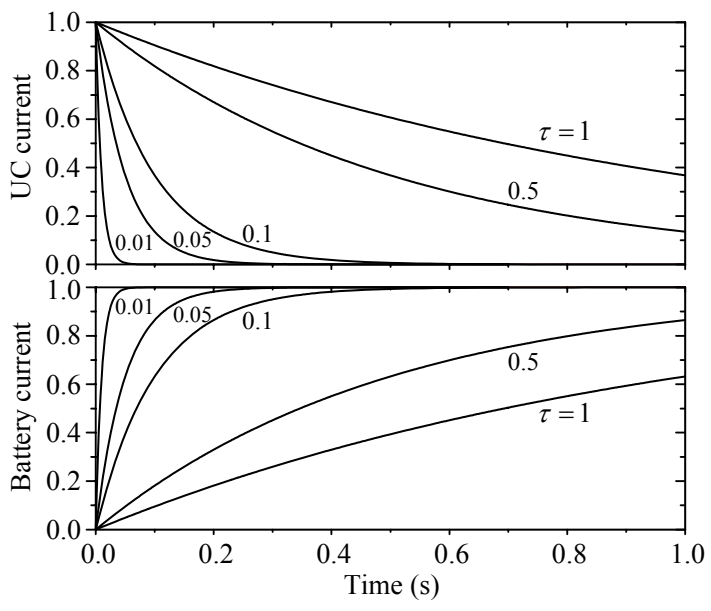

Figure 4: Low-pass filter at different time constant.

Since the UC can be rapidly charged or discharged, it is used to provide transient current to lower the changing rate of the battery current. The current distribution between the battery and UC is controlled by low-pass filter, which is given by: 


$$
\begin{aligned}
& I_{U C r e f}=I_{r e f}\left(1-\frac{1}{\tau s+1}\right) \\
& I_{\text {Bref }}=I_{r e f} \frac{1}{\tau s+1}
\end{aligned}
$$

where $\tau$ is the time constant. Given a unit step input, the output of the low-pass filter is shown in Figure 4.

\section{Simulation Results}

The multi-hybrid energy system is simulated in Matlab/Simulink with the parameters shown in Table 1.

Table 1: Simulation parameters.

\begin{tabular}{c|c|c}
\hline Name & Value & Unit \\
\hline$V_{T E}$ & 34.64 & $\mathrm{~V}$ \\
\hline$r_{T E}$ & 6 & $\Omega$ \\
\hline$V_{P V}$ & 28.44 & $\mathrm{~V}$ \\
\hline$r_{P V}$ & 3.37 & $\Omega$ \\
\hline$C_{1}$ & 0.267 & $\mathrm{uF}$ \\
\hline$C_{2}$ & 0.655 & $\mathrm{uF}$ \\
\hline$T_{s}$ & 0.02 & $\mathrm{~ms}$ \\
\hline$L_{11}, L_{12}$ & 550 & $\mathrm{uH}$ \\
\hline$L_{21}$ & 300 & $\mathrm{uH}$ \\
\hline$L_{31}, L_{32}$ & 220 & $\mathrm{uH}$ \\
\hline$\tau$ & 0.04 & $\mathrm{~s}$ \\
\hline$V_{B}$ & 12 & $\mathrm{~V}$ \\
\hline$C_{U C}$ & 2.2 & $\mathrm{~F}$ \\
\hline$C_{2}$ & 1000 & $\mathrm{uF}$ \\
\hline$R_{\text {load }}$ & 2.6 & $\Omega$ \\
\hline
\end{tabular}

From Fig. 5, it can be found that the maximum power points of the TEG and PVG are tracked simultaneously by tuning the duty cycle of the driving signals of the TE-PV Cuk-Cuk MIC. When a sudden load is applied, the UC branch will be discharged to provide the transient power and reduce the impact to the battery by tuning the driving signals of the UC-B DC-DC MIC, as shown in Fig. 6. The corresponding current transients are recorded at inductors $L_{31}$ and $L_{32}$, which are denoted as "UC branch" and "Battery branch", respectively.

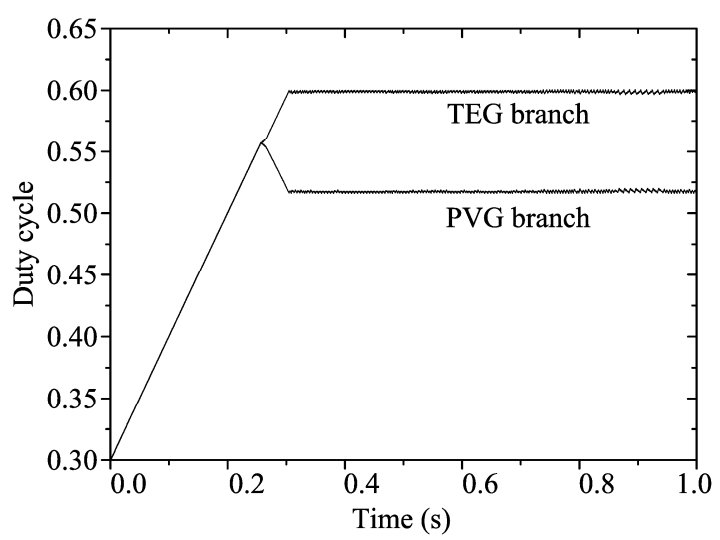

(a)

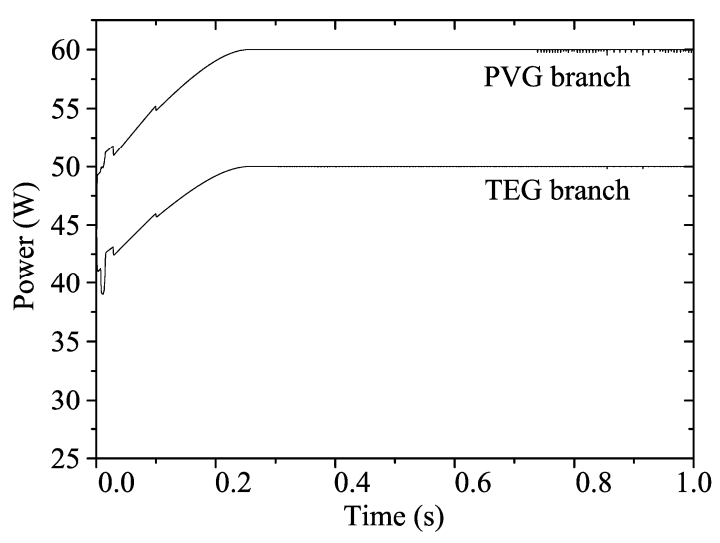

(b)

Figure 5: MPPT of TE-PV subsystem. (a), Duty cycle vs. time. (b), Power vs. time.

\section{Conclusion}

In this paper, a multi-hybrid energy system is proposed and implemented for HEVs, which combines the TEG and PVG hybrid subsystem, UC and battery hybrid subsystem. It offers the advantages of both the TE-PV hybrid subsystem and the UC-B hybrid subsystem. Compared with the previous TE-PV energy system, the proposed multi-hybrid system can draw the maximum power from the TEG and PVG, and offer stable output bus voltage. With MPPT and power balance control, the merits and performances of the proposed system are simulated. 


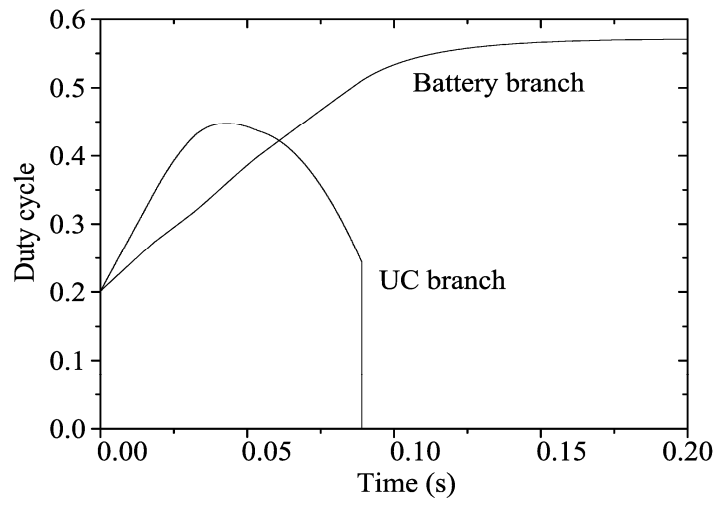

(a)

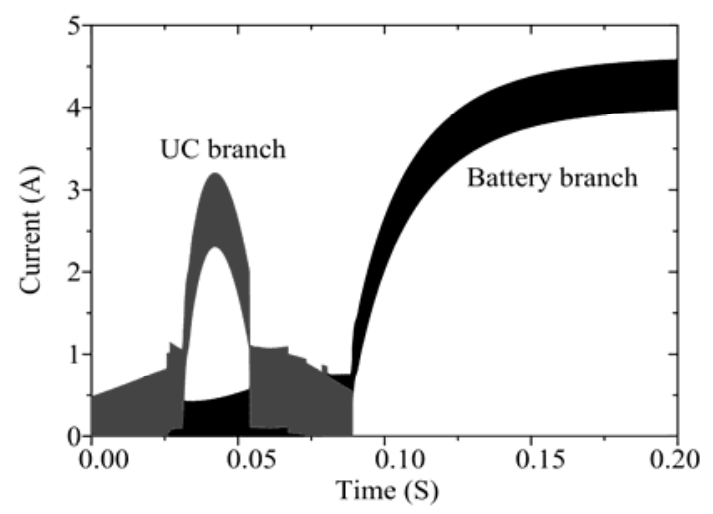

(b)

Figure 6: Power balance of UC-B subsystem. (a), Duty cycle vs. time. (b), Current vs. time.

\section{Acknowledgments}

This work was supported by a grant (Project code: 200807176032) from the Committee on Research and Conference Grants, The University of Hong Kong, Hong Kong Special Administrative Region, China.

\section{References}

[1] C. C. Chan and K. T. Chau, "An overview of power electronics in electric vehicles," IEEE Transactions on Industrial Electronics, Vol. 44, No. 1, Feb. 1997, pp. 3-13.

[2] C. C. Chan, "The state of the art of the electric, hybrid, and fuel cell vehicles," Proceedings of the IEEE, Vol. 95, No. 4, pp. 704-718, Apr. 2007.

[3] C. Yu, K. T. Chau and C. C. Chan, "Thermoelectric waste heat energy recovery for hybrid electric vehicles," Proceedings of 23rd International Electric Vehicle Symposium, Dec. 2007, Paper No. 21.

[4] K. T. Chau, Y. S. Wong and C. C. Chan, "An overview of energy sources for electric vehicles," Energy Conversion and Management, Vol. 40, No. 10, pp. 1021-1039, July 1999.

[5] K. T. Chau and Y. S. Wong, "Hybridization of energy sources in electric vehicles," Energy Conversion and Management, Vol. 42, No. 9, pp. 1059-1069, June 2001.

[6] X. Zhang and K. T. Chau, "An automotive thermoelectric-photovoltaic hybrid energy system using maximum power point tracking," Energy Conversion and Management, Vol. 52, No. 1, pp. 641-647, Jan. 2011.

[7] S. Niu, K. T. Chau and J. Z. Jiang, "Analysis of eddy-current loss in a double-stator cuprotor PM machine," IEEE Transactions on Magnetics., Vol. 44, No. 11, pp. 4401-4404, Nov. 2008.

[8] S. Niu, K. T. Chau, J. Z. Jiang and C. Liu, "Design and control of a new double-stator cup-rotor permanent-magnet machine for wind power generation," IEEE Transaction on Magnetics, Vol. 43, No. 6, pp. 2501-2503, June 2007.

[9] C. Liu, K. T. Chau and X. Zhang, "An efficient wind-photovoltaic hybrid generation system Using doubly-excited permanentmagnet brushless machine," IEEE Transactions on Industrial Electronics, Vol. 57, No. 3, pp. 831-839, Mar. 2010.

[10] S. Niu, K.T. Chau and C. Yu, "Quantitative comparison of double-stator and traditional permanent magnet brushless machines," AIP Journal of Applied Physics, Vol. 105, No. 7, Feb. 2009, Paper No. 07F105.

[11] X. Zhang and K. T. Chau, "Design and implementation of a new thermoelectricphotovoltaic hybrid energy system for hybrid electric vehicles," Electric Power Components and Systems, Vol. 39, No. 6, pp. 511-525, Apr. 2011.

[12] S. Niu, K. T. Chau, J. Li and W. Li, "Eddycurrent analysis of double-stator inset-type permanent magnet brushless machines," IEEE Transactions on Applied Superconductivity, Vol. 20, No. 3, pp. 10971101, Oct.2009.

[13] Y. Fan, K. T. Chau and S. Niu, "Development of a new brushless doubly fed doubly salient machine for wind power generation," IEEE Transactions on Magnetics, Vol. 42, No. 10, pp. 3455-3457, Oct. 2006. 
[14] X. Zhang, K. T. Chau, C. Yu and C. C. Chan "An optimal solar-thermoelectric hybrid energy system for hybrid electric vehicles," Proceedings of IEEE Vehicle Power and Propulsion Conference, Sep. 2008, pp. 1-6.

[15] X. Zhang, K. T. Chau and C. C. Chan, "Design and implementation of a thermoelectric-photovoltaic hybrid energy source for hybrid electric vehicles," World Electric Vehicle Journal, Vol. 3, pp. 1-11, Dec. 2009.

[16] M. S. W. Chan and K. T. Chau, "A switched-capacitor boost-multilevel inverter using partial charging," IEEE Transactions on Circuits and Systems II, vol. 54, no. 12, Dec. 2007, pp. 1145-1149.

[17] M. S. W. Chan, K. T. Chau and C. C. Chan, "A new switched-capacitor inverter for electric vehicles," Journal of Asian Electric Vehicles, Vol. 4, No. 2, pp. 905-909, Dec. 2006.

[18] K. T. Chau, New constant-frequency multiresonant boost convertor, IEE Electronics Letters, Vol. 30, No. 2, pp. 101-102, Jan. 1994.

[19] X. Zhang, K. T. Chau and C. C. Chan, "Overview of thermoelectric generation for hybrid vehicles," Journal of Asian Electric Vehicles, Vol. 6, No. 2, pp. 1119-1124, Dec. 2008 .

[20] K. T. Chau, C. C. Chan, and Y. S. Wong, "Advanced power electronic drives for electric vehicles," Electromotion, Vol. 5, No. 2, pp. 42-53, Apr.-June 1998.

[21] K. T. Chau and Z. Wang, "Overview of power electronic drives for electric vehicles, HAIT Journal of Science and Engineering B: Applied Sciences and Engineering," Vol. 2, No. 5-6, pp. 737-761, Dec. 2005.

[22] X. Zhang, K. T. Chau and C. C. Chan, "Overview of power networks in hybrid electric vehicles," Journal of Asian Electric Vehicles, Vol. 8, No. 1, Jun. 2010, pp. 1371-1377.

[23] C. Yu and K. T. Chau, "Thermoelectric automotive waste heat energy recovery using maximum power point tracking," Energy Conversion and Management, Vol. 50, No. 6, pp. 1506-1512, June 2009.

[24] C. Yu, K.T. Chau, X. Liu and J.Z. Jiang, " $A$ flux-mnemonic permanent magnet brushless motor for electric vehicles," Journal of Applied Physics, Vol. 103, No. 7, Apr. 2008, Paper No. 07F103, pp. 1-3.

[25] A. F. Burke, "Batteries and ultracapacitors for electric, hybrid, and fuel cell vehicles," Proceedings of IEEE, Vol. 95, No. 4, pp. 806820, Apr. 2007.

[26] W. X. Shen, C. C. Chan, E. W. C. Lo and K. T. Chau, "Adaptive neuro-fuzzy modeling of battery residual capacity for electric vehicles," IEEE Transactions on Industrial Electronics, Vol. 49, No. 3, pp. 677-684, June 2002.

[27] W. X. Shen, C. C. Chan, E. W. C. Lo and K. T. Chau, "Estimation of battery available capacity under variable discharge currents," Journal of Power Sources, Vol. 103, No. 2, pp. 180-187, Jan. 2002.

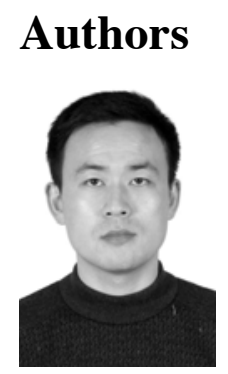

Dr. Xiaodong Zhang received his B.Eng. and M.Eng. degrees from Department of Automation, Tianjin University, China, in 2002 and 2005, respectively, and the Ph.D. degree in the University of Hong Kong, Hong Kong, China, in 2011. His research interests include the application of renewable energy sources, motor control and power electronics.

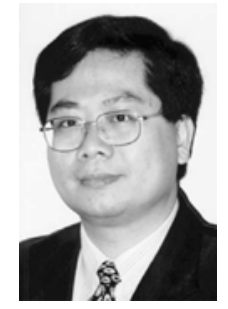

Prof. K. T. Chau is the professor in Department of Electrical and Electronic Engineering and Director of International Research Centre for Electric Vehicles at the University of Hong Kong. His research interests are electric vehicles, machines \& drives, clean energy and power electronics. In these areas, he has published over 300 refereed technical papers. Prof. Chau is also a Fellow of IET.

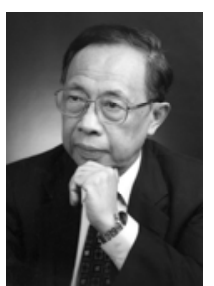

Prof. C. C. Chan is currently an honorary professor in the University of Hong Kong. He has authored 4 books, published over 120 technical papers, and held 7 patents. Prof. Chan is also a Fellow of the Royal Academy of Engineering, U.K., an Academician of the Chinese Academy of Engineering, the Ukraine Academy of Engineering Science, and both IEEE and IET. 